\title{
The Role of Emotional Intelligence in Counterproductive Work Behavior
}

\author{
Irene Samanta*, Sofia Kallou \\ Department of Business Administration, University of West Attica, Aegaleo-Athens, Greece \\ Email address: \\ isamanta@uniwa.gr (I. Samanta), redfaros@gmail.com (S. Kallou) \\ ${ }^{*}$ Corresponding author
}

To cite this article:

Irene Samanta, Sofia Kallou. The Role of Emotional Intelligence in Counterproductive Work Behavior. European Business \& Management. Vol. 6, No. 2, 2020, pp. 20-27. doi: 10.11648/j.ebm.20200602.11

Received: January 25, 2020; Accepted: February 20, 2020; Published: May 29, 2020

\begin{abstract}
The purpose of the present research is to investigate the role of emotional intelligence in counterproductive work behavior in the Local Government Organizations. The relationship between counterproductive work behavior, emotional intelligence and job satisfaction is also explored. A quantitative empirical survey was conducted in the public sector and especially in the Municipality of Chalkida, in Greece. The research findings have shown that job satisfaction has a negative correlation with counterproductive work behavior and positive correlation with emotional intelligence. Additionally, counterproductive work behavior \& emotional intelligence are influenced by age. Emotional intelligence has high score among the employees of the Municipality of Chalkida and this indicates a low tendency to exhibit counterproductive work behavior. The generalisation of the findings are potential limited by the fact that the sample consisted only of employees within a particular local government. Ebracing such surveys by local governments will be of use to resources management strategies and plans so as to improve human resources performance and create a work environment that is as optimal as possible. Additionally, they will improve citizens service and that will lead to a better reputation and value of the public organisations. The present study contributes to the literature on emotional intelligence and counterproductive work behavior in the work place by investigating the relationship between them.
\end{abstract}

Keywords: Emotional Intelligence, Job Satisfaction, Counterproductive Work Behavior, Local Government

\section{Introduction}

The role of emotional intelligence (EI) in the workplace is considered crucial as it is linked to employees performance, leadership effectiveness [1], job satisfaction (JB) [2] interpersonal relationships and a reduced counterproductive work behavior (CWB). Empirical research has concluded that when employees improve their emotional intelligence counterproductive behaviors decrease [3]. People with high levels of emotional intelligence have more control over their own emotions (self-control), can manage them better and are less likely to engage in deviant behaviors. It is also estimated that an employee with high levels of EI has an asset in any area of his life. These individuals are more satisfied with their work efficiency and can achieve high levels of work performance regardless of their education and skills $[4,5,6]$.

It is also considered that employees' behaviors and emotional state has a significant role in the functioning, performance and credibility of businesses \& organizations [7, 5]. Work behaviors that are considered to be counterproductive can have serious impact for both the organization as well as the individuals [8].

In addition, in today's era of globalization and intense competition [9] the new public management approach [10] tries to combine efficiency with the performance of public organizations as well as to provide accountability in order to improve citizens' satisfaction through the public services offered.

Therefore, the study of emotional intelligence (EI) in local government organizations and especially in the Municipality of Chalkida is of particular interest as these organizations contribute significantly to meet their citizens' needs and to solve their daily problems. A significant proportion of these employees is in a daily contact with citizens while their role is closely linked to the needs of each local community and at the same time there is a significant social interaction. 
This study draws attention to the role of EI and CWB in employees of local government organizations. More specifically, the research problem concerns the in-depth study of the phenomenon of EI in combination with the phenomenon of CWB among the local government employees. Consequently, this empirical research will help to draw useful conclusions about any interactions between EI and CWB and provide the basis for the development of future public management plans in the local government in Greece.

\subsection{Emotional Intelligence (EI)}

According to the researchers, EI has occupied the field of management and organizational psychology and behavior over the last decades [5]. This was the result of at least three decades of research in the field of social psychology with a focus on cognitive processes and emotions [11] Throughout this period, individual differences in the understanding, experience and expression of emotions [12] were investigated as well as the emotional state of the individual to the extent that he or she is affected by cognitive processes (memory, critical thinking) [11]. EI in particular, is popular in consulting companies and the media in general. For example, a consulting firm in its advertising material argued that: The EI is responsible for over $85 \%$ of the outstanding performance of top leaders [13].

Furthermore, Atkinson [2] argued that individuals' EI is associated with motivation that directly affects their performance. In his research he found that individuals differ in how they approach a goal, depending on the strength of their motivation (strong motivation). On the other hand, Wolf et al. [16] have studied the impact of EI on leadership in selfmanaged groups and found that empathy plays an important key while Sosik and Megerien [3] highlighted the relationship between EI and self-efficacy on leadership as leaders with high levels of EI feel confident they can take control over and believe they have control over their own lives.

Salovey and Mayer [4] are at the forefront of shaping EI theory by defining it as "the ability of a person to control and regulate his or her emotions and emotional reactions to himself and others, to be able to distinguish them and to use the information that emerges from them to guide his thinking and actions".

\subsection{Emotional Intelligence (EI) and Working Environment}

The influence of EI in the work environment has increased significantly in recent years. Particularly, Goleman [19] linked EI to leadership giving this relationship special value. Also in a study by Vakola et al. [1] has been found that leadership in executives provides positive feedback to their subordinates on their leadership and is considered to have a comparative advantage over other executives. At the same time, it enhances flexibility in decision-making and significantly preserves the identity of the organization [5]. Much of the research has focused on investigating the relationship between EI and work performance. An extensive
US survey has found that two out of three competencies that are considered essential for success are emotional competencies [5, 19]

In addition, people with high levels of EI can have greater adaptability and flexibility and face more positively difficult situations that may arise in business. Moreover, these employees appear to be more creative and energetic which highlights how important EI is as a tool to promote and improve business behavior [20, 21].

EI positively affects many aspects of an organization's staff such as their social and interpersonal relationships, cooperation and level of trust within the work environment [22]. This implies that the proper adoption of EI in an organization (emotional intelligent) directly affects its progress and well-being [20].

\subsection{The Impact of EI on Demographic Characteristics}

According to Vacola [1] the degree of impact of EI on demographic characteristics mainly concerns the age and experience of the individual. In addition, other studies have shown that occupational status is influenced by the level of EI and also at high positions the EI is more important than the educational level $[19,20]$ This is the following research hypothesis:

H1: There is a difference in the employees' level of EI with respect to demographic characteristics (age, experience, hierarchy position, level of education)

\subsection{Job Satisfaction (JS)}

Job Satisfaction (JS) is perhaps one of the most discussed topics in organizational behavior, human resources management and management [23]. The definition given by Locke [6] describes it as "the pleasant or positive emotional state resulting from the evaluation of one's experiences" and is probably one of the most widely used definitions found in job satisfaction literature.

In general, it can be considered that job satisfaction is an emotional response to a job that comes from comparing actual results with those that are desired [24]. There is also the opposite view that JS is not a single overall attitude but many individual attitudes to different aspects of the job. Also, empirical research has highlighted several aspects that affect EI to varying degrees, such as [6]:

Employees, on average, are satisfied with their job, the subject matter of the job and their bosses and colleagues.

Employees tend to be less satisfied with their salary and prospects without being fully clear.

\subsection{Counterproductive Work Behavior (CWB)}

Counterproductive Work Behavior is considered as unfair behaviors in the workplace [23] which have significant economic, sociological and psychological consequences. In particular, CWB refers to dysfunctional and divergent workplace behaviors which affect both employees and organizations.

According to Marcus and Schuler [8] the behavior of 
employees is in contrast with the goals of the organization. It mainly deals with deviant behaviors such as deliberate low performance, long breaks, sabotage, theft, aggressive behavior towards colleagues and clients, gossip, bullying, bribery and sexual harassment. Harris and Ogbonna [9] estimated that the negative impact of CWB on services and public organizations is immediate and actions may adversely affect clients / citizens with regard to the credibility and reputation of the organization.

These behaviors are usually attributed to negative emotions, such as envy, jealousy, anger and can lead to physical or psychological violence. Research has shown that people with negative emotions are more likely to adopt deviant behaviors in the workplace. For example, if they are angry they will lead others to become angry and also aggressive possibly leading to escalation of negative behavior with unintended consequences in the workplace [11].

\subsection{The Impact of CWB on Demographic Characteristics}

The impact of CWB on demographic characteristics, as evidenced by the literature review concerns the exploration of individual-to-individual variety. Thus, it is appropriate to investigate possible demographic characteristics that influence the way it occurs.

H2: There is a difference in the CWB of employees with respect to demographic characteristics (age, experience, hierarchy position, level of education)

\subsection{Emotional Intelligence (EI) and Job Satisfaction (JS)}

Empirical research has shown that JS, job performance and EI are related. Workers with high levels of EI have higher JS and they can optimally manage their emotions. Schreier [10] (as cited in Karadimas and Karadima [5]) argues that employees with positive emotions are more efficient and consistent in their work than those with negative emotions. In general, empirical studies have shown that EI is closely related to JS. In particular, recent research has shown that managers with a high level of EI produce positive and altruistic work behaviors and that their employees enjoy greater JS and performance.

Managers with a high degree of flexibility can facilitate the performance of their employees by managing these emotions that promote greater creativity, resilience and consistency allowing these employees to act [23]. In addition, executives with a high degree of flexibility should be more experienced in cultivating more positive interactions among employees to promote more collaboration [14] coordination [18] and behaviors that contribute to performance $[15,12]$.

H3: Emotional Intelligence of employees affects their Job Satisfaction

\subsection{Emotional Intelligence (EI) and Counterproductive Work Behavior (CWB)}

Martin et al. [12] consider that EI plays an important role in preventing negative behaviors. Mayer et al. [11] have explained that if employees' EI is improved deviant behaviors related to their work behavior will be greatly reduced indicating a negative relationship between EI and CWB [17]. In addition, Spector [13] suggested that CWB derives from confusion in human relationships and lack of autonomy among other factors, while Glomb [14] argued that individual characteristics of employees (eg, feelings or aggression) were determinants of the CWB. According to Marcus and Schuler [8], as well as Hepworth \& Towler [15], reported self-control as a critical element of CWB as emotional intelligence is the ability to control one's emotions. Thus, those who control one's self have excellent ability to perform emotional work and this would adversely affect employee CWB [11].

Additionally, Salgado [16] \& Colbert et al. [17] noted that the emotional stability of employees would adversely affect the creation of CWB. Austin et al. [18] like Mavroveli et al. [19], argued that lack of EI causes not only negative behaviors in organizations but also antisocial behaviors whereas Siu [20] has acknowledged the causal link between EI and negative behaviors. In conclusion, when employees cannot control their emotions they are likely to fail in social relationships [17] and experience negative emotions resulting in CWB $[18,19]$.

H4: Employees' Emotional Intelligence affects states of Counterproductive Work Behavior

\subsection{Job Satisfaction (JS) and Counterproductive Work Behavior (CWB)}

From a conceptual perspective based on inductive reasoning it appears that people who have a negative opinion of their work experience would be more likely to participate in CWB events. Theoretically, several theories provide conceptual support for such a connection by a motivational approach [10]. There are two related conceptual arguments that are particularly relevant to understanding the relationship between job satisfaction and CWB: social exchange theory $[11,12]$ and the rule of reciprocity [13]. In summary, these theoretical models predict that employees respond to unhappy conditions and unfair workplaces by engaging in behavior that harms the organization or other employees. Based on 25 studies and a sample size of 6,106 individuals, Dalal [7] reported a correlation between overall JB and CWB similar to that of Judge, Thoresen, Bono, and Patton [21] who correlated it with job performance. In addition, in a recurrent on-site survey study, Judge, Scott, and Ilies [22] found that employees reported engaging in more behaviors that were counterproductive on days that they were less satisfied with their work than on days when they were more satisfied.

H5: Job Satisfaction of employees affects their degree of Counterproductive Work Behavior (CWB)

\section{Methodology}

\subsection{Research Methodology}

This empirical research is characterized as a case study which focuses on recording the views of local government 
employees regarding EI and CWB at work.

The research was conducted in the public sector and especially in the municipality of Chalkida. The selection of local government in this study was based on the important role of it due to its increased competences and proximity to the local community as well as the resolution of the daily problems of citizens in multiple areas.

Local government in Greece has always played an important role in providing local public goods and services as undertakes the promotion of the demands of local communities (needs, problems, etc.) to the central government so that the central government can include them in its central planning. They also offer services to citizens to cover the geographical inability of the public administration to directly control every part of a state [25].

\subsection{Measures}

This research was based in three (3) questionnaires:

Emotional Intelligence TEIQue-test is the most easy tool to use for measuring emotional intelligence as a personality trait available in 15 languages. The complete test consists of 15 subscales and 153 questions in total organized according to four (4) factors: well-being, self-control, emotion and sociality. TEIQue V. 1.00 and V. 1.50 questionnaire have been adapted to Greek as well as its extended and short version [26].

Minnesota Satisfaction Questionnaire [27]: for the responses a 5-point Lickert-type scale (1-dissatisfaction, 2dissatisfaction, 3-neutral, 4- satisfaction, 5-degree satisfaction) was used.

Counterproductive Work Behavior tool by Fox and Spector [23] for the responses a 5-point Lickert-type scale (1-Never, 2-Once or Twice, 3-Every Month, 4-Once - Twice a Week, 5Every Day) was used.

\subsection{Data Analysis}

The following statistical methodology was used in this empirical study:

1. Descriptive (demographic) presentation of the sample for better presentation of the sample and interpretation of its aspects.

2. Assessment of hypotheses regarding research objectives. Sample regularity test (Gauss distribution) was performed for correct selection of statistical tests / techniques (utilizing parametric or non parametric statistics). For the purpose of the Data Analysis SPSS was used.

\section{Results}

\subsection{Participants}

In this empirical study, a total number of 90 administrative employees of the Municipality of Chalkida participated. The majority of the survey sample is women (73.3\%) compared to just $26.7 \%$ men while the absolute majority is $46-60$ age $(52.2 \%)$ followed by ages $31-45(42.2 \%)$. The majority of the research participants is high school graduates (44.4\%) and there is an additional $17.8 \%$ who hold a postgraduate degree. High school graduates have a significant proportion in the sample $(28.9 \%)$, completed by an $8 \%$ of Vocational College graduates while there are no Elementary-High School graduates. The majority of the sample also has work experience in the public sector between 6 and 25 years (63.3\%). Specifically, from 6-15 years $31.1 \%$, $16-25$ years $32.2 \%$, up to 5 years $22.2 \%$ and only $24.4 \%$ with more than 25 years of experience.

\subsection{Descriptive Analysis}

\subsubsection{Analysis of EI}

The strongest elements of EI are those related to individual activity (mean=3.99), ease of adapting to new situations \& environments (mean=3.90), a sense of being good to themselves (mean=3.90), optimism about their lives $($ mean=3.88) and that they can step in and understand one another's emotions (mean=3.86).

Less 'strong' mathematical values (in fact most disagree with these proposals) there is a lack of affection in nearby people (mean=1.8), complaints about one's behavior (mean=1.94), lack of motivation (mean=1.97) and lack of attachment even with nearby individuals (mean=1.97) (Table 1).

Table 1. EI: Descriptive Statistics, mean and standard deviation.

\begin{tabular}{lll}
\hline $\mathrm{N}$ & Valid & 90 \\
Mean & Missing & 0 \\
Median & & 3,8101 \\
Mode & 3,8500 \\
Std. Deviation & 4,00 \\
Variance &, 39103 \\
Range &, 153 \\
Minimum & 1,77 \\
Maximum & 2,90 \\
\hline
\end{tabular}

\subsubsection{Analysis of JS}

The strongest elements of JS are the opportunity to capitalize on the employee's qualifications (mean=4.46), the ability to work continuously on projects (mean=4.4), the ability to do things according to his consciousness $($ mean $=4.4)$ and finally, the opportunity to do things for other people $($ mean $=4.36)$.

The least robust figures relate to the way in which the public administration is exercised (mean=2.37), the remuneration offered in proportion to the work provided (mean=2.38) and the existing working conditions $($ mean=2.97) (Table 2).

Table 2. JS: Descriptive Statistics, mean and standard deviation.

\begin{tabular}{lll}
\hline & & index JS \\
\hline $\mathrm{N}$ & Valid & 90 \\
Mean & Missing & 0 \\
Median & & 3,7467 \\
Mode & 3,8500 \\
Std. Deviation & 3,85 \\
Variance &, 43934 \\
\hline
\end{tabular}




\begin{tabular}{ll}
\hline & index JS \\
\hline Range & 2,15 \\
Minimum & 2,55 \\
Maximum & 4,70 \\
\hline
\end{tabular}

\subsubsection{Analysis of $C W B$}

The most aggravating factors in terms of CWB are those related to delayed work without permission (mean=2.21) and take breaks beyond the permitted (mean=1.92).

The least aggravating factors in terms of $\mathrm{CWB}$ are the destruction of colleagues (mean=1.01), the concealment of colleagues' objects (mean=1.03) and intentional harassment of a colleague's work $($ mean=1.06). (Table 3$)$

Table 3. CWB: Descriptive Statistics, mean and standard deviation.

\begin{tabular}{lll}
\hline & & index CWB \\
\hline $\mathrm{N}$ & Valid & 90 \\
& Missing & 0 \\
Mean & & 1,4171 \\
Median & 1,3300 \\
Mode & 1,00 \\
\hline
\end{tabular}

\begin{tabular}{ll}
\hline & index CWB \\
\hline Std. Deviation &, 40583 \\
Variance &, 165 \\
Range & 2,00 \\
Minimum & 1,00 \\
Maximum & 3,00 \\
\hline
\end{tabular}

\subsection{Analysis of Research Hypotheses}

H1: There is a difference in the employees' level of EI with respect to demographic characteristics.

From all the demographic factors, only age affects emotional intelligence. The significance level (a) is defined as: 0.05 One-way ANOVA is chosen because of the regularity of the EI index and also because there are two variables [28].

1. Age category: independent categorical variable $(\geq 3$ groups)

2. EI index: dependent variable (arithmetic). Through SPSS we get the following results:

Table 4. One-way Fluctuation Analysis Scoreboards (EI-Age).

\begin{tabular}{|c|c|c|c|c|c|c|c|c|}
\hline \multicolumn{9}{|c|}{ Descriptives } \\
\hline \multicolumn{9}{|c|}{ Index EI } \\
\hline & \multirow{2}{*}{$\mathbf{N}$} & \multirow{2}{*}{ Mean } & \multirow{2}{*}{ Std. Deviation } & \multirow{2}{*}{ Std. Error } & \multicolumn{2}{|c|}{ 95\% Confidence Interval for Mean } & \multirow{2}{*}{ Minimum } & \multirow{2}{*}{ Maximum } \\
\hline & & & & & Lower Bound & Upper Bound & & \\
\hline $18-30$ & 5 & 3,1600 & ,37941 & , 16968 & 2,6889 & 3,6311 & 2,90 & 3,83 \\
\hline $31-45$ & 38 & 3,8511 & ,39859 & ,06466 & 3,7200 & 3,9821 & 3,03 & 4,60 \\
\hline $45-60$ & 47 & 3,8462 & ,32692 & 04769 & 3,7502 & 3,9422 & 3,27 & 4,67 \\
\hline
\end{tabular}

\begin{tabular}{lllll}
\hline ANOVA & & & & \\
\hline Index EI & Sum of Squares & df & Mean Square & F \\
\hline Between Groups & 2,238 & 2 & 1,119 & 8,562 \\
Within Groups & 11,370 & 87 &, 131 & \\
Total & 13,608 & 89 & & \\
\hline
\end{tabular}

Statistical significance in the ANOVA table $(\mathrm{F}=8,562$, Sig. $=0,000)$ indicates that the $F$ value is statistically significant $(<0.05)$, and also statistically significant differences between age groups (between 18-30) were observed. Categories 31-45 \& 45-60, where the average goes up as they get older) and especially the EI index between 1830 and $31-45$ but not between $31-45$ and $45-60$ years (F $[2.87]=8.562, \mathrm{p}<0.05)$. Therefore, the null hypothesis does not apply. From the results we conclude that there is a difference in the degree of EI of employees with respect to the age category.

H2: There is a difference in the CWB of employees with respect to demographic characteristics

From all the demographic factors only age affects CWB. The significance level (a) is defined as: 0,05 Use of nonparametric Kruskal Wallis test due to CWB Index irregularity.

It is found that the null hypothesis is rejected and the alternative applies: There is a difference in the CWB of employees with respect to the age category.
In particular, statistical distribution of the CWB Index by age group is shown in the following table.

Table 5. Distribution Table Age-CWB.

\begin{tabular}{lll}
\hline \multicolumn{1}{l}{ Statistics $^{\mathbf{a}}$} & & \\
\hline Index CWB & & 5 \\
\hline $\mathrm{N}$ & Valid & 0 \\
Mean & Missing & 2,3720 \\
Median & & 2,2700 \\
Std. Deviation &, 60903 \\
a. Age=18-30 & \\
\hline & \\
\hline Statistics ${ }^{\text {a }}$ & \\
\hline Index CWB & & \\
\hline N & Valid & 38 \\
Mean & Missing & 0 \\
Median & & 1,2950 \\
Std. Deviation & 1,2700 \\
a. Age=31-45 &, 26993 \\
\hline
\end{tabular}




\begin{tabular}{lll}
\hline Statistics $^{\mathbf{a}}$ & & \\
\hline Index CWB & & \\
\hline $\mathrm{N}$ & Valid & 47 \\
Mean & Missing & 0 \\
Median & & 1,4143 \\
Std. Deviation & 1,3300 \\
a. Age=45-60 &, 34110 \\
\hline
\end{tabular}

H3: Emotional Intelligence of employees affects their Job Satisfaction

The Spearman correlation coefficient is used to test the research hypothesis since at least one of the variables is abnormal (Job Satisfaction) (Table 6).

The significance level (a) is defined as: 0.05

Table 6. Correlation Analysis EI-JS.

\begin{tabular}{ll}
\hline Correlation & indicator EI- indicator JS \\
\hline Correlation Coefficient & 0,345 \\
Sig.(2-tailed) & 0,001 \\
$\mathrm{~N}$ & 90 \\
\hline
\end{tabular}

Statistical significance is found between the two indexes $(<0.05)$ but with a moderately positive correlation (when one variable increases, the other increases respectively) and so the alternative holds: Job satisfaction of employees is affected by the level of Emotional Intelligence

H4: Employees' Emotional Intelligence affects states of Counterproductive Work Behavior

The Spearman correlation coefficient is used to test the research hypothesis since at least one of the variables is abnormal distribution (Counterproductive Behavior in the Working Environment) (Table 7): The significance level (a) is defined as: 0.05

Table 7. Correlation Analysis EI-CWB.

\begin{tabular}{ll}
\hline Correlation & index EI - index CWB \\
\hline Correlation Coefficient & 0,114 \\
Sig.(2-tailed) & 0,284 \\
$\mathrm{~N}$ & 90 \\
\hline
\end{tabular}

Based on the results non-statistical significance is found between the two indexes $(>0.05)$ so the null hypothesis $\mathrm{H} 0$ is valid. Therefore, we conclude that the degree of EI of employees does not affect states of $C W B$.

H5: Job Satisfaction of employees affects their degree of Counterproductive Work Behavior

The Spearman correlation coefficient is used to test the research hypothesis since both variables are abnormal (Table 8):

The significance level (a) is defined as: 0.05

Table 8. Correlation Analysis JS-CWB.

\begin{tabular}{ll}
\hline Correlation & index JS - index CWB \\
\hline Correlation Coefficient &,- 340 \\
Sig.(2-tailed) & 0,001 \\
$\mathrm{~N}$ & 90 \\
\hline
\end{tabular}

Statistical significance is found between the two indexes $(<0.05)$ but with a moderately negative correlation (when one variable increases, the other decreases respectively) and so the alternative holds: Job Satisfaction of employees affects Counterproductive Work Behavior.

\section{Discussion}

In the present case study, an extensive effort was made despite its small sample size of 90 employees to investigate the role of EI and behaviors in the workplace of local authorities. More specifically:

EI is the highest indicator in the current study. In addition, it was found that participants were exceptionally happy with their lives as in case of the majority of researchers who report that people with EI are more satisfied with their lives and thus can be more effective in the work environment [20]. In addition, the majority of participants control their emotions in combination with the ability to easily adapt to new environments and conditions. This is also in line with the researchers who report people with high levels of EI manage and control their lives and emotions more effectively.

EI was found to be positively correlated with job satisfaction as agreed by the majority of researchers [4] and is influenced by age. The literature is partly in line with the findings of the present study as environmental factors such as age and experience have been found to influence $[1,5,19]$. Specifically, regarding the age factor the present study found a positive correlation (the higher the age, the higher the EI).

CWB is markedly diminished as it is perceived by all participants as unfair behavior in the workplace. That is why they report more behaviors such as absences or delays that are more "painless" than hiding things from colleagues or deliberate harassment. Also, according to the results of CWB the majority of participants $(>70 \%)$ shows little to no counterproductive behavior in the working environment. This is in line with both the higher scores of EI and self-control found in the present study as emotional intelligence refers to the ability to better control the emotions that negatively affect employees' CWB [12, 10, 11] but also and the relationship between EI and counterproductive behavior. Finally, age affects person-to-person counterproductive behaviors [16].

Job satisfaction was high for local government employees. Specifically, high scores were found regarding the interesting work environment (project production capability, freedom to perform, qualifications and also the permanence of the Greek State) although objections arisen from the function of the public administration as a whole and in particular the remuneration offered. It is also linked to the EI and CWB as documented in the literature $[4,5,6]$. As relevant empirical research has shown there is a negative association between JS and CWB in particular with unjustified absences and workplace delays. The more satisfied an employee is the fewer absences and delays he / she has made [12, 13]. In particular, JS in the present study is negatively correlated with CWB and is also associated with very low levels of CWB as shown in the literature $[11,15]$. Concerning EI, there is a positive correlation with corresponding empirical studies which report that JS is influenced by EI [4]. 


\section{Conclusions}

In the present empirical study EI has the highest score among the employees and this also indicates the low tendency to display counterproductive work behaviors. There is also quite high job satisfaction among the employees in the workplace. JS is negatively correlated with CWB and positively with EI. CWB is influenced by the age of employees (the younger they are, the more likely are to develop CWB). EI also is influenced by the age of employees (the older employees have higher levels of EI).

Hence, it might be concluded that emotional intelligence is an important soft skill that when is in high levels among the employees it affects their satisfaction in the workplace and may lead to low counterproductive work behaviors. The high levels of job satisfaction is also correlated with low tendencies in counterproductive work behaviors and that affects both the employees and the organization. An organization with emotional intelligent and satisfied employees with low levels of counterproductive work behaviors may affect citizen satisfaction too with regard to credibility and reputation of it. Adoption from the organisations of appropriate human resource management strategies and plans that focus on the emotional intelligence is considered valuable so that to improve human resource performance and satisfaction and create a work environment that is as optimal as possible adding value to the organisation.

\section{Study Limitations and Suggestions for Future Research}

Research on the investigation of EI and behaviors in the local government in the current socio-economic recessions is a useful endeavor in Greece where the impact of memorandum has not yet been overcome (unemployment, income reduction, over-taxation).

The present study is an initial attempt for investigation using a quantitative technique (questionnaire use). It is proposed that the research would be extended by using hybrid methodologies (mixed use of qualitative methodology - interviews - mixed research) in order to investigate in depth the phenomenon of CWB in relation to EI and also other factors than job satisfaction such as performance, commitment, stress etc.

In addition, there were restrictions on the sample size as the research was restricted to the administrative staff of the Municipality of Chalkida. The generalisation of the findings are potential limited by the fact that the sample consisted only of employees within a particular local government. For this reason a future study should use a more representative sample in different local organizations.

\section{References}

[1] Vakola, M. and Nikolaou, I. (2012). Organizational Psychology and Behavior. Athens: Rosili Publications.

[2] Atkinson, J. W. (1964). An indtroduction to motivation. Van
Norstrand.

[3] Sosik, J. J. and Megerian, L. E. (1999). Understanding leader emotional intelligence and performance: the role of self-other agreement on transformational leadership perceptions. Group and Organization Management 24, 3, pp. 340-66.

[4] Salovey, P., \& Mayer, J. D. (1990). Emotional intelligence. Imagination, Cognition, and Personality, 9, 185-211.

[5] Karadimas, Th. and P. Karadimas, (2016). The Relationship between Emotional Intelligence and Effective Leadership. EJournal of Science \& Technology, 11 (4), pp. 55-70, http://ejst.teiath.gr.

[6] Locke, E. A. (1976) The Nature and Causes of Job Satisfaction. In Dunnette, M. D., Ed., Handbook of Industrial and Organizational Psychology, Vol. 1, 1297-1343.

[7] Dalal, R. S., (2005) A meta-analysis of the relationship between organizational citizenship behavior and counterproductive work behavior. Journal of Applied Psychology 90 (6), 1241-1255.

[8] Marcus, B., \& Schuler, H. (2004). Antecedents of counterproductive behavior at work: A general perspective. Journal of Applied Psychology, 89, 647-660.

[9] Harris, L. C., \& Ogbonna, E. (2006). Service sabotage: A study of antecedents and consequences. Journal of the Academy of Marketing, 34, 543-558.

[10] Schreier, Lori, (2002), Emotional Intelligence and Mediation Training, Conflict Resolution Quarterly, Vol. 20, No. 1, p. 107.

[11] Mayer, J. D., Roberts, R. D., and Barsade, S. G., (2008). Human Abilities: Emotional Intelligence. The Annual Review of Psychology. Vol. 59, pp. 507-36.

[12] Martin, J. M., Knopoff, K., Beckham, C., 1998. An alternative to bureaucratic impersonality and emotional labor: bounded emotionality at the body shop. Administrative Science Quarterly 43 (2), 429-470.

[13] Spector, P. E., 1997. The role of frustration in antisocial behavior at work. In: Giacalone, R. A., Greenberg, J. (Eds.), Antisocial Behavior in Organizations. Thousand Oaks, Sage, CA, pp. 1-17.

[14] Glomb, T., 2002. Workplace anger and aggression: informing conceptual models with data from specific encounters. Journal of Occupational Health Psychology 7 (1), 20-36.

[15] Hepworth, W., Towler, A., 2004. The effects of individual differences and charismatic leadership on workplace aggression. Journal of Occupational Health Psychology 9 (2), 176-185.

[16] Salgado, J. F., 2002. The Big Five personality dimensions and counterproductive behaviors. International Journal of Selection and Assessment 10 (1/2), 117-125.

[17] Colbert, A. E., Mount, M. K., Harter, J. K., Witt, L. A., Barrick, M. R., (2004). Interactive effects of personality and perceptions of the work situation on workplace deviance. Journal of Applied Psychology 89, 599-609.

[18] Austin, E. J., Saklofske, D. H., Egan, V., (2005). Personality, well-being, and health correlates of trait emotional intelligence. Personality and Individual Differences 38 (3), $547-558$. 
[19] Mavroveli, S., Petrides, K. V., Rieffe, C., Bakker, F., (2007) Trait emotional intelligence, psychological well-being and peer-rated social competence in adolescence. British Journal of Developmental Psychology 25, 263-275.

[20] Siu, A. F. Y., 2009. Trait emotional intelligence and its relationships with problem behavior in Hong Kong adolescents. Personality and Individual Differences 47 (6), $553-557$.

[21] Judge TA, Thoresen CJ, Bono JE, Patton GK. (2001). The job satisfaction-job performance relationship: A qualitative and quantitative review. Psychological Bulletin, 127, 376- 407.

[22] Judge TA, Scott BA, Ilies R. (2006). Hostility, job attitudes, and workplace deviance: Test of a multi-level model. Journal of Applied Psychology, 91, 126-138.

[23] Fox, S. and Spector, E. P. (2003), Counterproductive Work Behavior Checklist Items by Subscale - CWB-C 45 item, http://shell.cas.usf.edu/ pspector/scales/cwbcpage.html (access 15/11/2018).
[24] Oshagbemi, T., 2000. Correlates of pay satisfaction in higher education. The International Journal of Educational Management, 14, 95-107. Rasmani, K. A.

[25] Iancu D. C. \& Klimovsky D. (2008), Thinking outside the box local government and the preference- holders' participation to policy making processes in Slovakia and Romania, 16th NISPAcee Annual Conference, 15-17, May, Bratislava.

[26] Petrides, K. V., Pita, R., \& Kokkinaki, F. (2007). The location of trait emotional intelligence in personality factor space. British Journal of Psychology, 98, 273-289.

[27] Minessota Satisfaction Questionnaire http://vpr.psych.umn.edu/instruments/msq-

(MSQ)

(1977) minnesotasatisfaction-questionnaire

[28] Nova-Kaltsouni X, (2006) Methodology of Empirical Research in the Social Sciences (in greek), Athens, Gutenberg. 